\title{
A Descriptive Study to Assess the Prevalence of Depression among the Adolscents People in Selected Community Area of Pune City
}

\author{
Authors \\ Miss. Lavina Ranbhise, Miss. Rutuja Patole, Miss. Shamal Patane \\ Mrs. Monita Thokchom Asst. Professor \\ Bharati Vidyapeeth Deemed University College of Nursing, Pune, India
}

\begin{abstract}
The objectives of the study were:-

- To assess the prevalence of depression among adolescents people.

-To associate the findings with selected demographic variables.

A non-probability convenience sampling technique was used for the study. The content validity of the tool was done by experts in the field of nursing. The tool consisted of demographic data and structured questionnaires. Data analysis was done by using descriptive statistics.
\end{abstract}

\section{Introduction}

Depression is a common mental disorder that presents with depressed mood and loss of interest. It is mainly due to adverse life events, disease or medications. It affects important mental and social functions, which depending on the severity might substantially impair a patient's abilities to carry out simple daily activities. Episodes might last for one year, be recurrent or become chronic. Fifteen per cent of patient will commit suicide if not treated. There are three main forms of treatment for depression: counselling and psychotherapy; electroconvulsive therapy (ECT); and antidepressant medications.

\section{Need for the Study}

Depression accounted for $4.5 \%$ of the global and $7.6 \%$ of the Indian burden of disease in the year 2002. Depression affects $3-15 \%$ of the general population; $0.4-5 \%$ of cases are severe. It affects mainly adults, women, and low-income groups. In young people, the prevalence of depression is $0.3 \%$ in preschool children; $2 \%$ in school children; and 4-8\% in adolescents. Children of both sexes are equally affected, but in adolescents, females are affected twice as often as males. The symptoms may include behavioural problems, social isolation and difficulties at school; thus depression is frequently misdiagnosed as "growing pains". Depression in adolescents is risk factor for depression and bipolar disorder during adulthood; drug or alcohol abuse; and suicide. Suicide is one of the major causes of adolescent mortality. As per previous researches and statistical data the information which I have gathered it denotes that there is higher incidence rate of depression among the elderly people in community area. 


\section{Problem Statement}

A descriptive study to assess the prevalence of depression among adolescents people in selected community areas of Pune city.

\section{Objectives of the Study}

1. To assess the prevalence of depression among adolescents people in community areas of Pune city.

2. To associate the findings with the selected demographic variables Condition

\section{Review of Literature}

"If earth is blessed with life, every living soul is also promised with the destined path called illnesses.”

-John Louisville

The purpose of review of literature is to obtain information of prevelence of depression among dolescent people.

\section{The Literature had been presented under following headings}

Literature related prevalence of depression in India. Literature related depression among adolescents in India.

Literature related prevalence of depression in India

Hamada T et. al., (2003), conducted a study on abnormal nocturnal blood pressure fall in senileonset depression with Sub cortical silent cerebral infarction. Results suggest that abnormal nocturnal blood pressure fall patterns appear to be Involved in the development of Sub cortical cerebral infarction in senile-onset depression.

Hamalanien et. al., (2005), conducted a study of major depressive episode related to long unemployment and frequent alcohol intoxication study, concluded that long time unemployment is associated with increased risk of major depressive episode. Frequent alcohol intoxication among long term unemployed individuals greatly increases the risk of depression.

Stordal et al., (2006), conducted study of recurrent unipolar major depression and executive functions, concluded that there is little evidence that unipolar major depression is uniquely associated with executive dysfunctions.

Suen and Dhar, (2006) stated that the prevalence of depression, which is common in residential homes $\mathrm{P}=0.04$ ), is not associated with the social support from outside the home, and the feelings of belonging towards the institution and other residents are more important than noninstitutional support.

Gerard sana cora (2008) conducted study on link of major depression to increased level of neurons in the brain, findings reveals that level of neurons in the brain with major depression had about $30 \%$ more nerve cells in regions of the thalamus involved with emotional regulation\& the regions appeared larger in patients with major depression.

\section{Literature related depression among adolescents}

Anuradha (2001) has found that depressive disorders, incorporate a spectrum of psychological functions which vary considerably in severity, frequency and duration. A critical issue in research of depression and its correlation with other variables is the frequency and expression of depressive cognitions and behaviours. This study examines the role of psychological and coping factors in depression by studying a group of 130 female and 132 male college and university students. Initial depression is the major predictor of final depression, subjects who are already depressed tend to be depressed when examined after 3-6 months and contributed significantly in the major depression.

Satapathy and Singhal (2001) compared stress, self-esteem, depression and academic performance of visually and hearing impaired adolescents. Results reveal that visually impaired are less stressed and depressed, has higher self esteem and academic performance than the hearing impaired adolescents. Hearing impaired adolescents also exhibit more number of behaviour problems. 
In their study Abela and Payne (2003) tested the stress and symptom components of the integration of the hopelessness and self-esteem theories of depression in a sample of third-and seventh-grade children. The results support the integrative theory and reveal that depressogenic inferential styles interacted with negative events to predict increases in hopelessness but not non hopelessness depression symptoms in boys with low but not high self esteem. At the same time, contrary to the integrative theory, depressogenic inferential styles interact with negative events to predict increases in hopelessness but not non hopelessness depression symptoms in girls with high but not low self-esteem.

The study by Dumont and Provost (2004) examined group differences on self-esteem, social support, different strategies of coping and different aspects of social life among 297 adolescents. Groups were classified into 3, based on the scores of depressive symptom and frequency of daily hassles namely, well adjusted, resilient and vulnerable. The results reveal that well adjusted adolescents have higher self-esteem than adolescents in the 2 other groups; resilient adolescents have higher self-esteem than vulnerable adolescents. The resilient and vulnerable adolescents have higher scores on antisocial and illegal activities than well adjusted adolescents. Finally resilient adolescents have higher scores on problem-solving coping strategies than adolescents in the two other groups.

Schorder (2004) conducted a study to test the utility of the Coping Competence Questionnaire (CCQ) in predicting depression among chronic disease patients. Hierarchical multiple regressions indicate moderator effects of coping competence in the relationship between symptom stress and depression. Symptom stress is strongly correlated with depression among patients who were low in coping competence only. Among patients high in coping competence, depression is low and unaffected by symptom stress

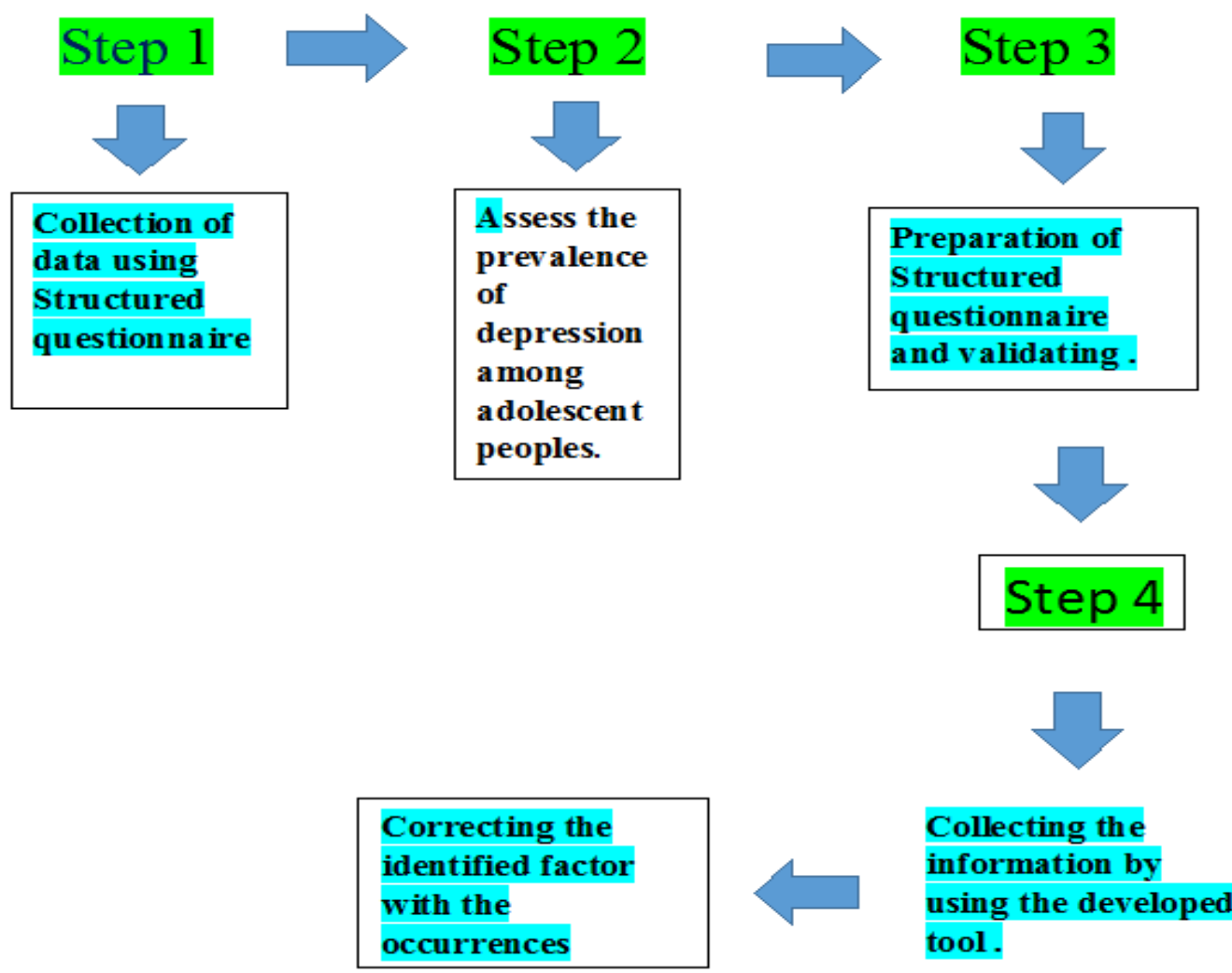

Fig 2 schematic representations of steps of the research design 


\section{Research Variavbles}

Qualities, attributes, properties of characteristic that are observed or measured in a natural setting without manipulating and establishing causes-and defect in relationship.

In this study, research variable is prevalence of depression among adolescent peoples.

\section{Setting of Study}

Setting refers the area where the study is conducted quantitative researcher deliberately strive to study their phenomenon in a variety of natural context.

The study was conducted in selected community area of Pune city. This community area of Pune city was chosen because this was convenient to the investigator this area has adequate numbers of adolescents are available with these setting was in a favour of selecting the research setting.

For pilot study a separated set of adolescent peoples had been chosen from the katraj, data nagar and area of pune city.

\section{Population}

According to Pilot study population entire aggregate designated set of criteria.

In this study all adolescents who were residing in community area and suffering from depression included in the selected populations.

\section{Inclusion Criteria: 200 Sample Size}

\section{Sampling and Sampling Technique}

In this study the sampoling technique is use is non probabli convenient sampling technique was adopted in the study.

Convenient sampling is also known accidental sampling. Convenient sampling is an inexpensive method. The samples are accessible and usually require less time to acquire. They provide the means to conduct studies on topics that cannot be examined with probability sampling. As the samples are selected purposively for the study it is also known as purposive sampling (Pilot)

\section{Sample Size}

A sample is subject of the population selected to participation in research study. the sample in the study consisted 200 adolescents who were residing in community area.

\section{Criteria for Sample Selection}

Criteria are the characteristics that delimit the population of interest.

\section{Inclusion Criteria}

1] Adolescents who are at the age of 11-20 years of age

\section{Data collection technique and tool}

Collection of data refers to a purposive gathering of information relevant to the subject matter under study and the methods used depend mainly on the nature, purpose and scope of the inquiry to be undertaken, as well as on the availability of resources and time. Tool is selected appropriately in a given situation, depending on the research approach, sample size, and laid down criteria etc.

A tool consisting of two parts were developed for data collection. The data was obtained from the adolescent peoples from community area Pune city.

Suggestions were obtained from experts in the field of Mental Health Nursing.

\section{Development of the tool}

The tool is most frequently a very concise, pre planned set of questions designed to yield specific information to meet a particular need for research.

A standardize tool (Ivan Goldberg screening for depression) for knowledge assessment regarding depression.

For the selection of the items and preparation of the tool, the following steps were taken.

Review of research and non-research literature was done. Opinion and suggestions were taken from experts, which helped in determining the important areas to be included. This was done the help of literature review and advice from experts. 


\section{Description of the tool}

\section{Standardized Tool}

The Structured tool consists of two sections:

Section I: this section seeks information on demographic data of adolescent peoples i.e. Gender, age, type of family, family income, religion, residence, occupation.

Section II: standardize tool (Ivan Goldberg screening for depression) for knowledge assessment regarding depression.

This section comprises of Structured questionnaire. This part consisted of 10 questions knowledge assessment regarding depression.

Each question has four options and according to the observation made by the observer on the knowledge of depression.

\section{Content Validity}

The content of data collection tool was send for its validity in terms of relevance and accuracy to a list of experts along with scoring sheet. The data collection tool was send to 5 experts and were received back with their valuable suggestions, all 5 experts are from mental health nursing (psychiatry) department total 5 experts were selected from Bharati Vidyapeeth College of nursing Pune.

Suggestions for modification and improvement of the tool were welcomed. Five experts gave suggestions about construction of question.

\section{Reliability}

The reliability was done at bharati hospital and research centre pune. The tool was administered to 6 samples selected as per the set criteria. The structured questionnaires method was used the scores were calculated separately and then given for statistical analysis

The method used for the reliability of tool was correlation coefficient method of reliability.

Method used: Karl's Pearson'sformula

Following formula gives coefficients and correlations of the reliability. Also data is collected by 2 persons so, $\sum x y$ gives the exact error in the reliability scores.

$$
r=\frac{n\left(\sum x y\right)-\left(\sum x\right)\left(\sum y\right)}{\sqrt{\left[n \sum x^{2}-\left(\sum x\right)^{2}\right]\left[n \Sigma y^{2}-(\Sigma y)^{2}\right]}}
$$

\section{Procedure for data Collection}

A Formal permission was obtained from the principal of Bharati Vidyapeeth College of nursing. the final study was conducted from December $26^{\text {th }}-2017$ to January $3^{\text {rd }}-2018$.

200 adolescent people were selected by convenience sampling method from community area of Pune city. The following schedule was followed for data collection:

In the present study this chapter deals with the analysis and interpretation of data collection from 200 sample of adolescent people to assess the prevalence of depression in selected community area of pune city.

\section{Objective of the study}

1. To assess the knowledge regarding depression.

2. To associate findings with selected demographic variables.

\begin{tabular}{|l|c|c|}
\hline Residence & 137 & $68.5 \%$ \\
Own house & 63 & $31.5 \%$ \\
Rent house & & \\
\hline Family income & 27 & $13.5 \%$ \\
5000 to 10000 & 173 & $86.5 \%$ \\
10000 above & & \\
\hline Religion & 166 & $83 \%$ \\
Hindu & 13 & $7.5 \%$ \\
Christian & 15 & $6.5 \%$ \\
Muslim & 6 & $6 \%$ \\
Other & & \\
Fathers occupation & 107 & $53.5 \%$ \\
Self-employed & 58 & $29 \%$ \\
Business & 35 & $17.5 \%$ \\
Government job & & \\
\hline Mothers occupation & 87 & $43.5 \%$ \\
Self-employed & 32 & $16 \%$ \\
Business & 66 & $7.5 \%$ \\
Government job & 15 & $33 \%$ \\
House wife & \multicolumn{2}{|l}{} \\
\hline
\end{tabular}




\begin{tabular}{|c|c|c|}
\hline Depression Scale & frequency & Percentage \\
\hline Mild & 36 & $18 \%$ \\
\hline Moderate & 163 & $81.5 \%$ \\
\hline Severe & 1 & $0.5 \%$ \\
\hline
\end{tabular}

Section 1 Demographic Data $\mathrm{N}=200$

\begin{tabular}{|c|c|c|c|}
\hline Sr no. & Age group & frequency & Percentage \\
\hline 1 & 12 to 15 & 99 & $49.5 \%$ \\
\hline 2 & 16 to 18 & 101 & $50.5 \%$ \\
\hline
\end{tabular}

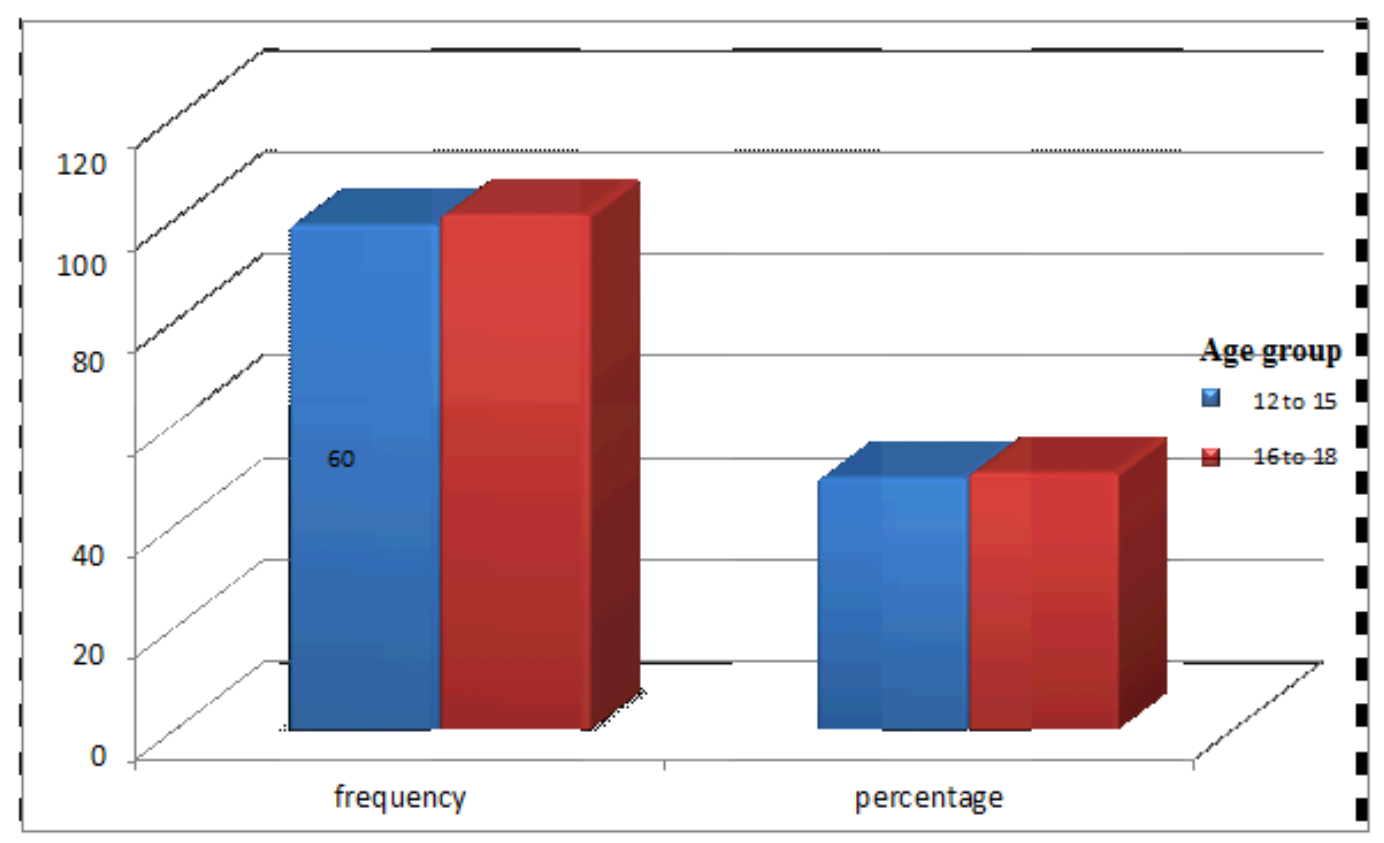

Figure -1 Shows that the age wise distribution of adolescent people in the selected community of pune city.

\begin{tabular}{|c|c|c|c|}
\hline Sr No. & Gender & Frequency & percentage \\
\hline 1 & male & 115 & $57.5 \%$ \\
\hline 2 & female & 85 & $42.5 \%$ \\
\hline
\end{tabular}

\section{Frequency \& percentage}

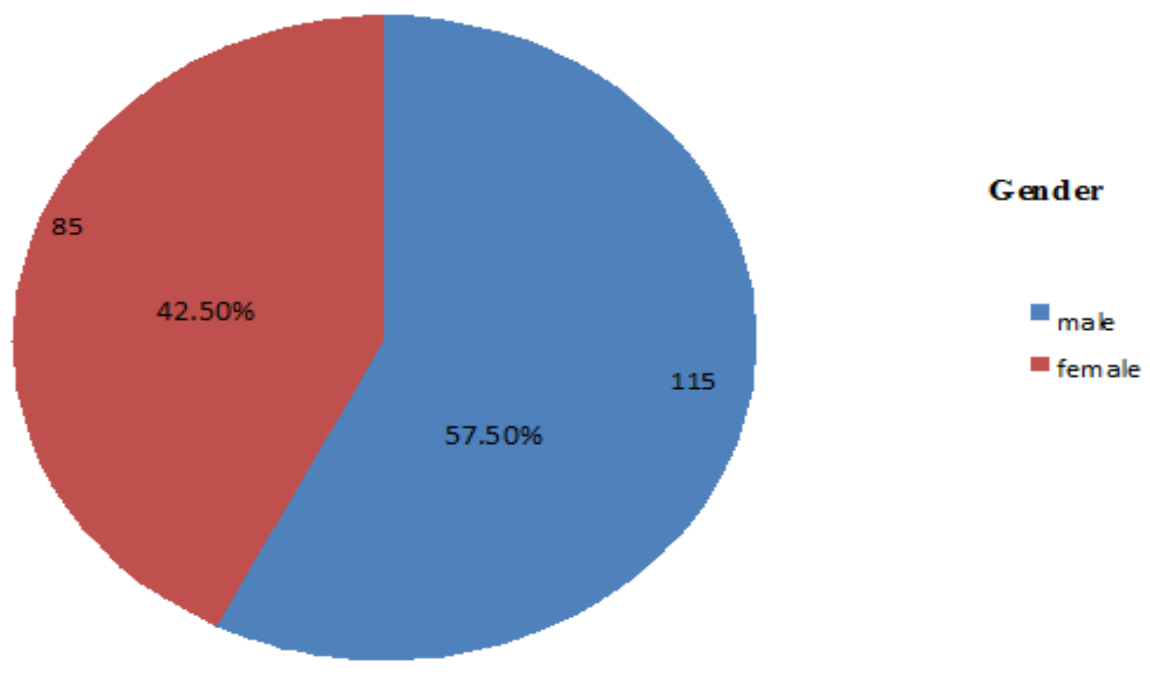

Figure No-2 Shows that the how many are male and female in this study. 


\begin{tabular}{|c|c|c|c|}
\hline Sr No & Family Income & Frequency & percentage \\
\hline 1 & 5000 to 9000 & 27 & $13.50 \%$ \\
\hline 2 & 10000 above & 173 & $86.50 \%$ \\
\hline
\end{tabular}

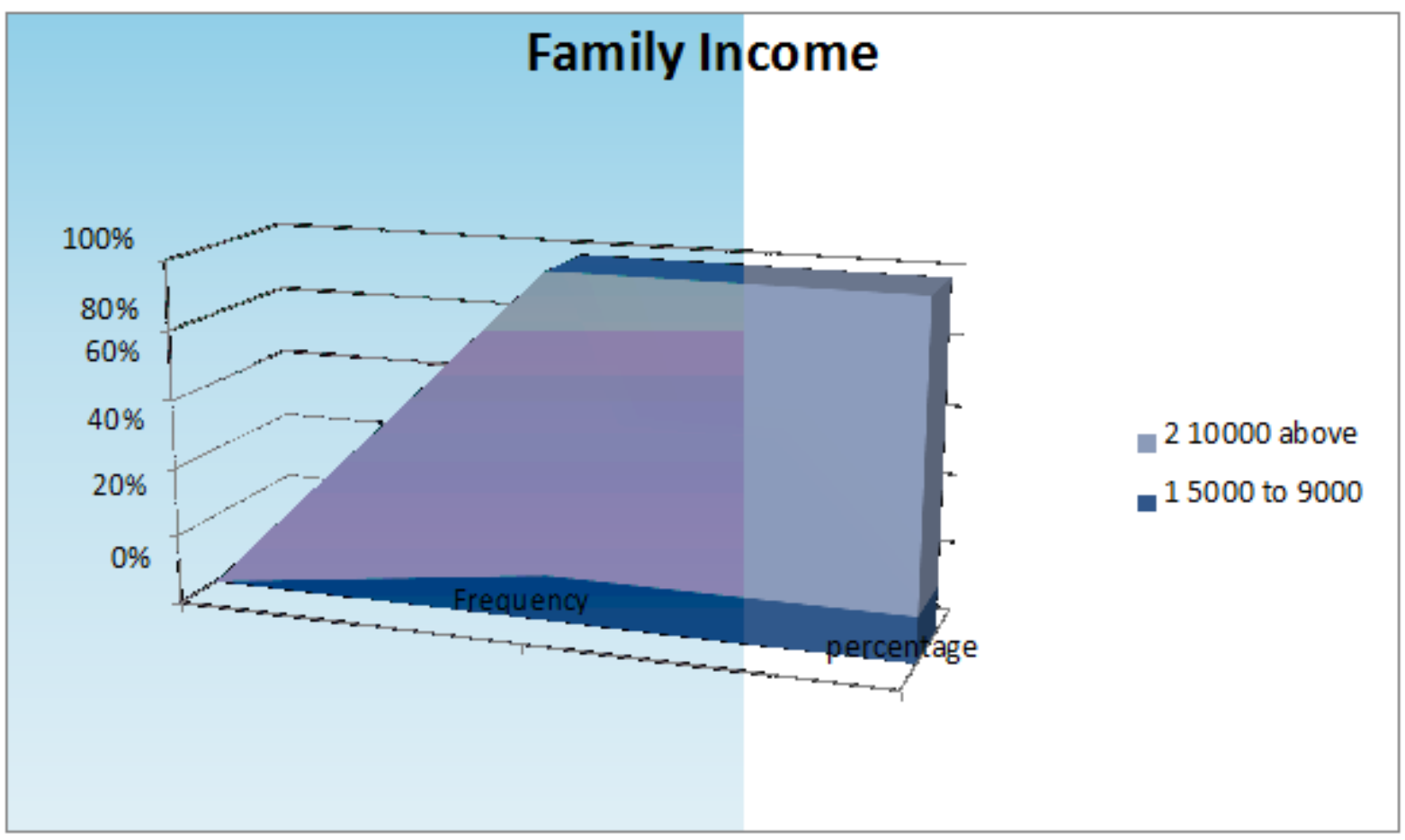

Figure No 3 Shows that the family income is distributed in to frequency and percentage

\begin{tabular}{|c|c|c|c|}
\hline Sr No & Residence & Frequency & percentage \\
\hline 1 & Own house & 137 & 68.5 \\
\hline 2 & Rent house & 63 & 31.5 \\
\hline
\end{tabular}

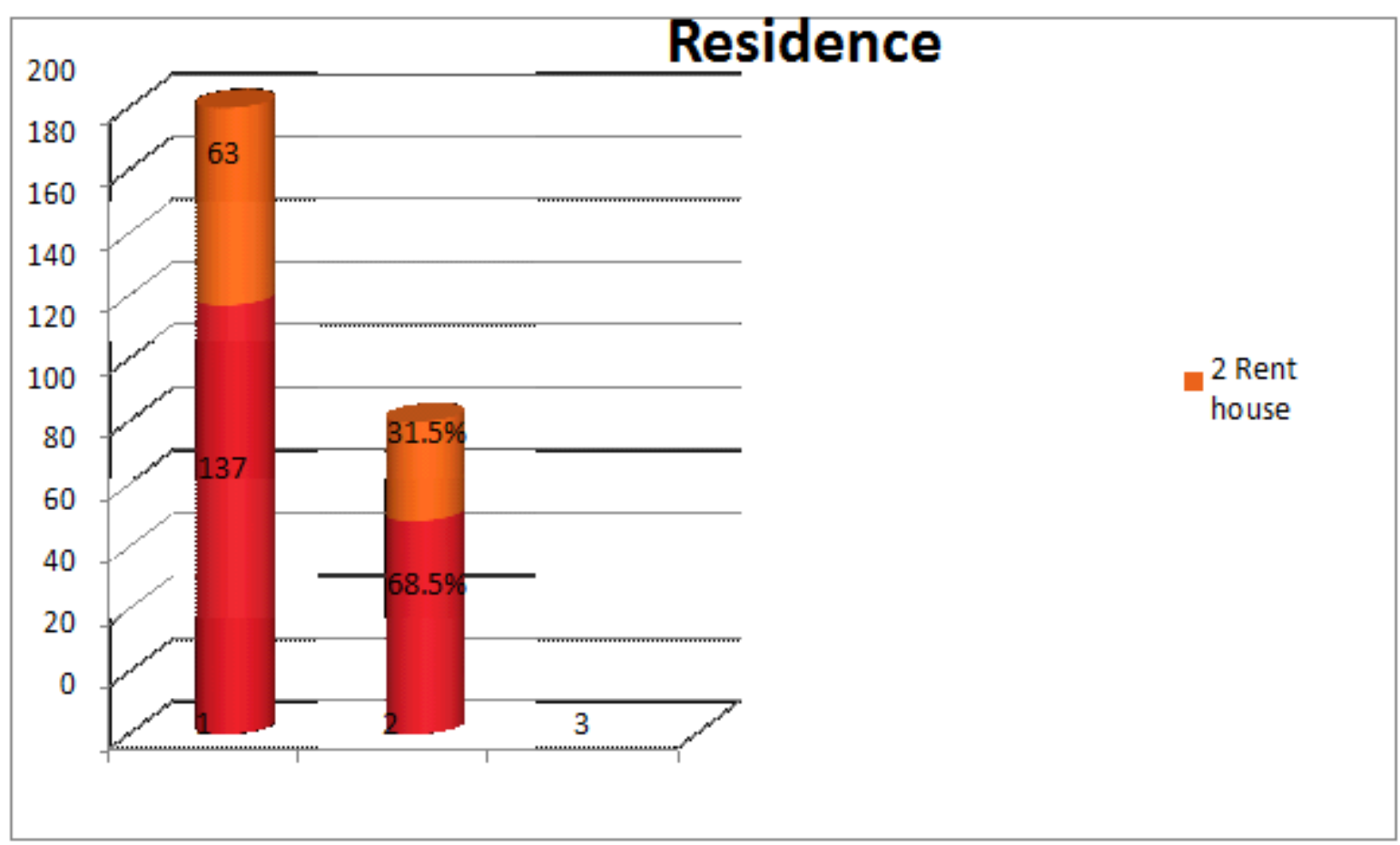

Figure No-4 Shows that the recidence of adolescent people in the selected community area of pune city 
JMSCR Vol||06||Issue||06||Page 311-321||June

\begin{tabular}{|c|c|c|c|}
\hline Sr No & Type Of Family & Frequency & Percentage \\
\hline 1 & Nuclear Family & 88 & $44.56 \%$ \\
\hline 2 & Joint Family & 112 & $56 \%$ \\
\hline
\end{tabular}

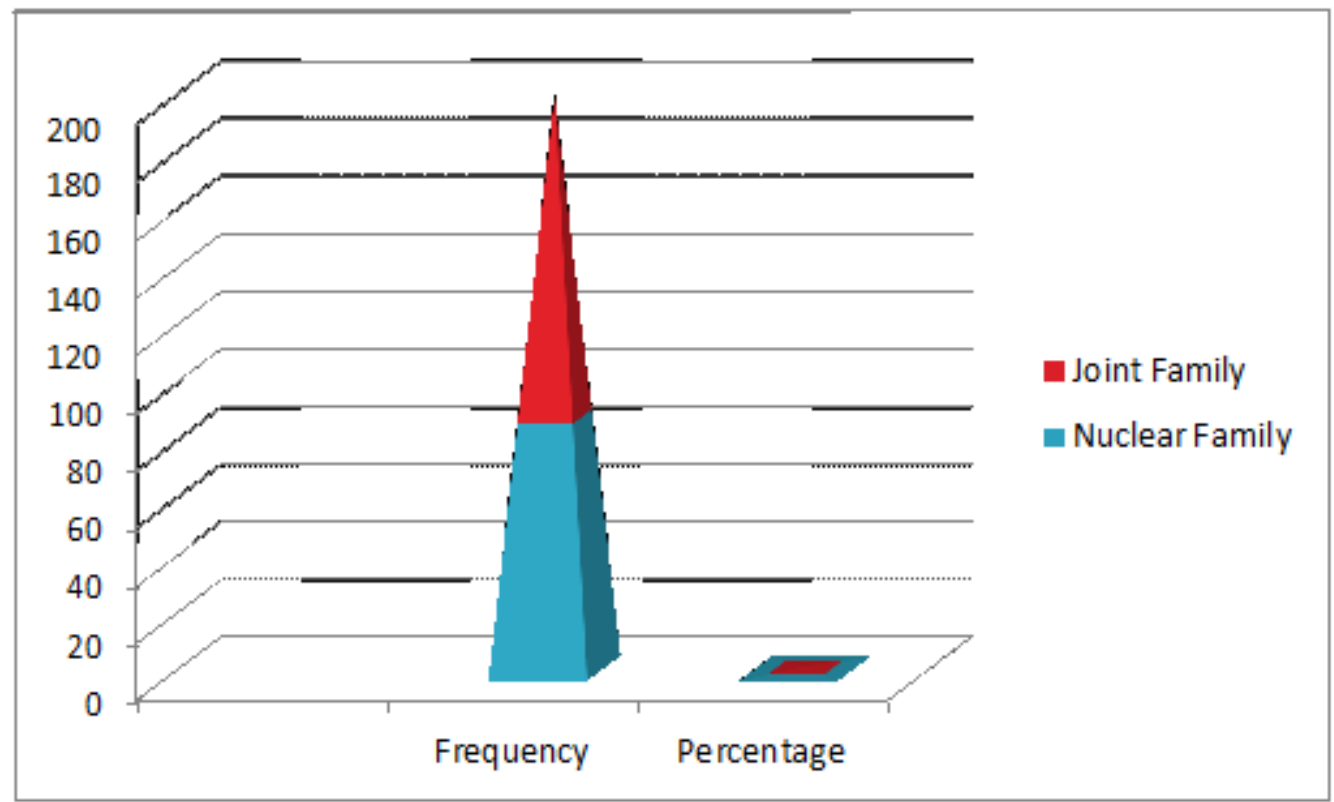

Figure No - 5 Shows that the type of family. there is joint family is more than nuclear family.

\begin{tabular}{|c|c|c|c|}
\hline Sr No & Religion & Frequency & Percentage \\
\hline 1 & Hindu & 166 & $83 \%$ \\
\hline 2 & Muslim & 15 & $7.50 \%$ \\
\hline 3 & christen & 13 & $6.50 \%$ \\
\hline 4 & Any Other & 6 & $3 \%$ \\
\hline
\end{tabular}

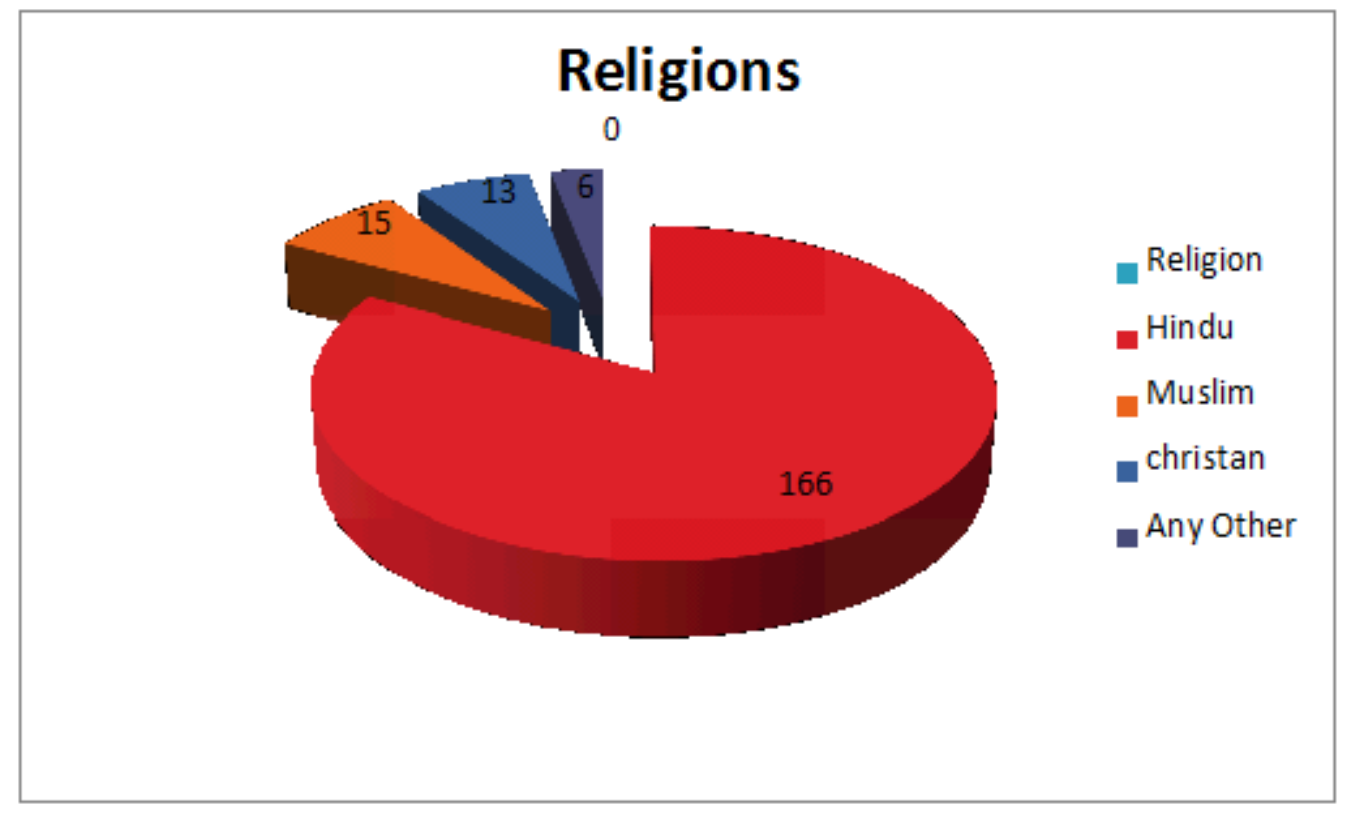

Figure No-6 Shows that the distribution of the religions 


\begin{tabular}{|c|c|c|c|}
\hline Sr No & Occupation & frequency & percentage \\
\hline 1 & Self employed & 107 & $53.50 \%$ \\
\hline 2 & business & 58 & $29 \%$ \\
\hline 3 & government & 35 & $17.50 \%$ \\
\hline
\end{tabular}

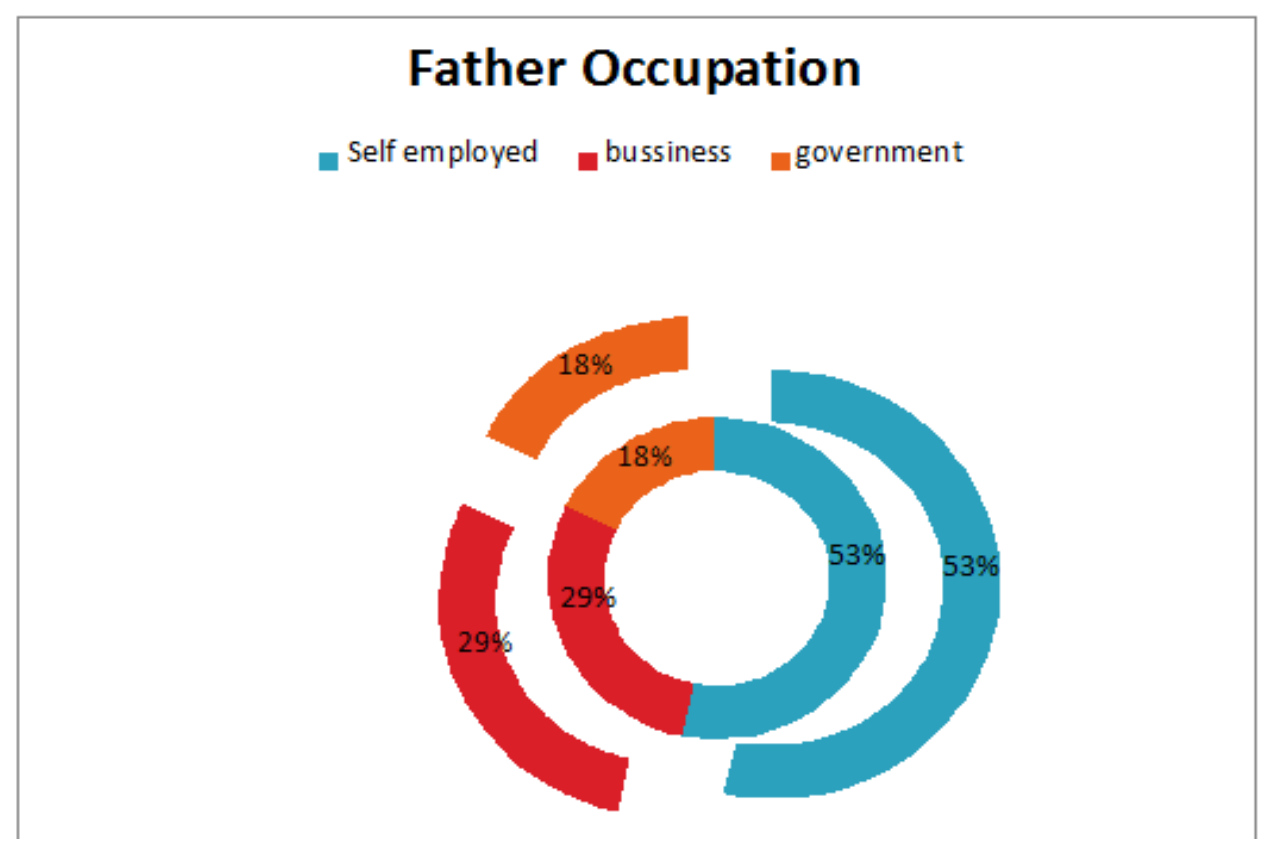

Figure No - 7 Shows that the Occupational status of their father

\begin{tabular}{|c|c|c|c|}
\hline SR No & Occupation & Frequency & Percentage \\
\hline 1 & Self Employed & 87 & $43.50 \%$ \\
\hline 2 & Business & 32 & $16 \%$ \\
\hline 3 & Government & 15 & $7.50 \%$ \\
\hline 4 & Housewife & 66 & $33 \%$ \\
\hline
\end{tabular}

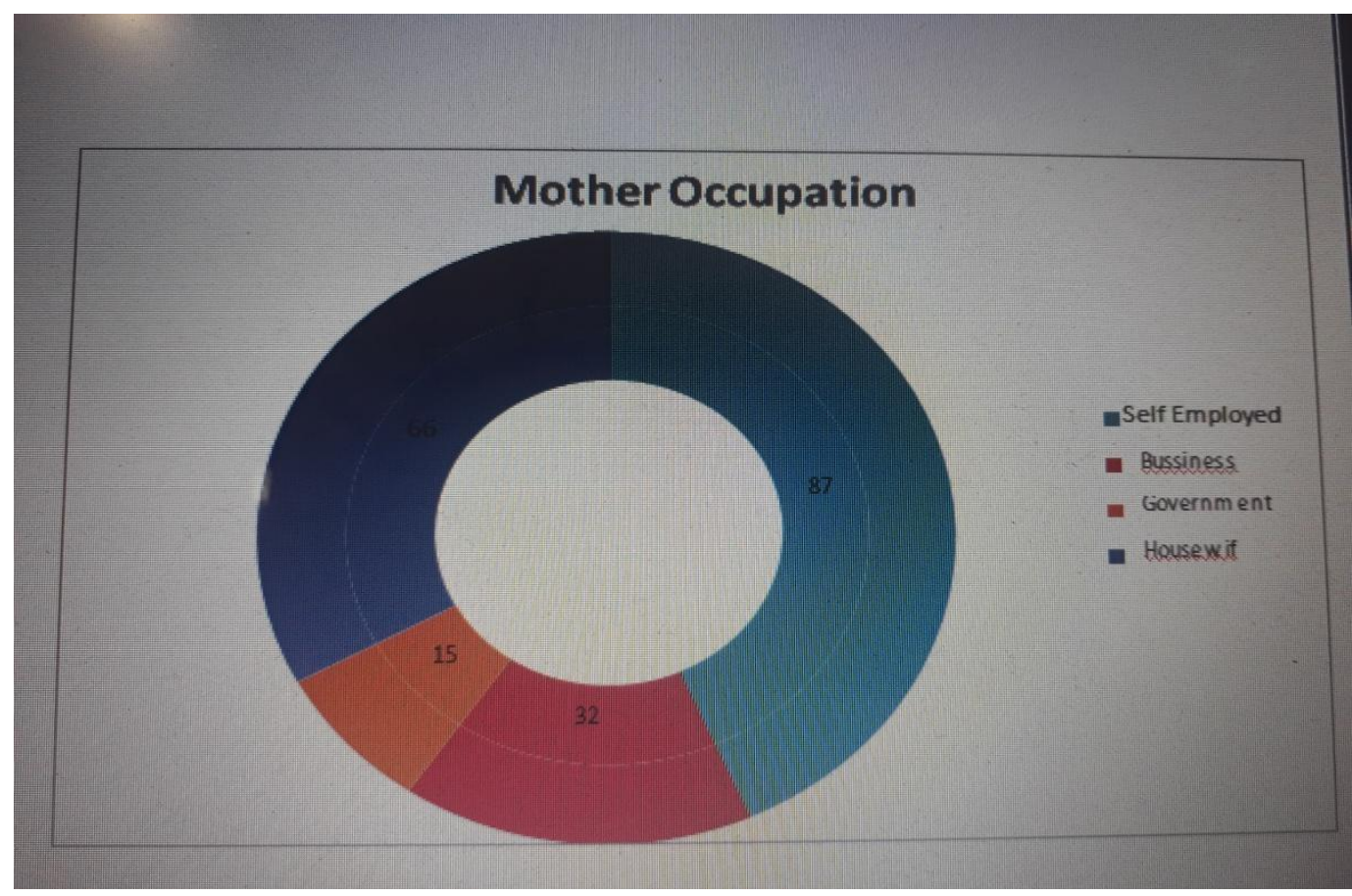

Figure No-8 Shows that the Occupational status of their mother. 


\begin{tabular}{|c|c|c|c|}
\hline Sr No & Depression Scale & Frequency & Percentage \\
\hline 1 & Mild Depression & 36 & $18 \%$ \\
\hline 2 & Moderate Depression & 163 & $81.50 \%$ \\
\hline 3 & Severe Depression & 1 & $0.50 \%$ \\
\hline
\end{tabular}

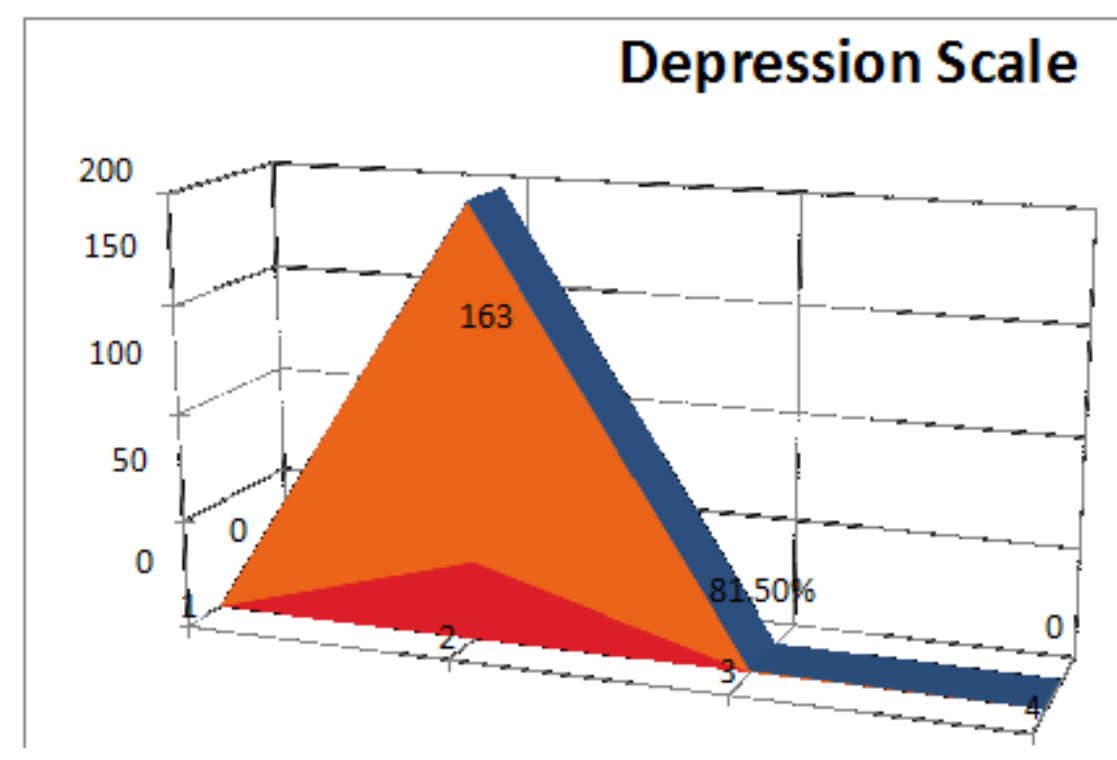

Figure No-9

Shows that by using test retest method and Assissing the prevalence of depression scale among adolescent people in community area of pune city. and the percentage are :

Mild $-18 \%$, Moderate $-81.5 \%$ and Severe $0.5 \%$.

\section{Recommendations}

Similar study can be under taken for large samples so that results can be generalize.

1. The same study can be done with an non experimental research approach having a control group.

2. A comparative study can be conducted using two different teaching strategies to educate the students in relation to procedural preparation, management, and prevention of depression among adolescents.

3. A video assisted teaching module can be prepared and tested for its effectiveness.

The chapter deals with the summary of the research study, bringing forth the major finding of the study, conclusion, nursing implication limitations and recommendations given at the end of the study.

\section{Limitation}

This study was limited to adolscents only the structured questionnaires $\mathrm{R}$ module had to be explained to sample personally as they found difficult to understand the questionnaires on depression.

\section{Summary}

This study is cross sectional descriptive study to assess the prevalence of depression

among adolescent people in selected community area of pine city using test retest sampling technique and sampling size was 200

The main Aim of the study was ...

To assess the prevalence of depression among adolescents people.

To associate the findings with selected demographic variables.

The major finding were: The maximum percentage students were in the age group of $16-$ 20 Years of age. And the minimum students were in the age group of 12 to 15 years of age. Maximum students of were male with $57.5 \%$ and $42.5 \%$ were the female. 
And by using non probability convenient sampling technique. Assissing the prevalence of depression scale among adolescent people in community area of pune city. and the percentage are :

Mild $-18 \%$, Moderate $-81.5 \%$ and Severe -0.5

\section{References}

1. Whitby M, Mclaws ML, Ross MW. Why Healthcare worker don't wash their hand: a behavioural explanation. Infect control Hosp Epidemiol 2006;484-92.

2. Kampf G, Kramer A, Epidemiologic background of hand hygiene and evalution of the most important agents for scrubs \& rubs. Clin Microbiol Rev 2004;863-93.

3. Gupta S. Williamsion S, Vij A. Knowledge and practice of nursing staff towards infections control measures in a tertiary care hospital. J Academy Hosp Admin 2007;13(2):12-8.

4. Haley RW, CulverDH, whiteJ, MorganWM, AmberTG, MannVP, et, et al. The efficacy of infection surveillance and control programs in preventing nosocomial infections in US hospitals. Am J Epidemiol 1985; 121:182205.

5. Webster RG. Influenza: an emerging disease. Emerg Infect Dis 1998;4(3).

6. Grayson ML and Russo PL (2009). The National Hand Hygiene Initiative. Medical Journal of Australia, 191(8),420421.

7. National Health and Medical Research Council (NHMRC) (2010). Australia Guidelines for the Prevention and Control of Infection in Healthcare. Commonwealth of Australia.

8. CDC (2009). Workbook for Designing, Implementing and Evaluating a Sharps Injury Prevention Program. http:/www.cdc.gov/sharpssafety/

9. World Health Organization (2000) WHO initiative on HIV/AIDS and sexually transmitted infections- An overview of selected curable sexually transmitted disease.

http:www.who.int/asd/figures/global_repo rt.html

10. Alice L. Price. The Art, Science and Spirit of Nursing, Philadelphia, WB Saunders Company, $3^{\text {rd }}$ Edition 1968.

11. McClosky, JC, Grace, HK Current issues in nursing, (4 $4^{\text {th }}$ ed.) St. Louis: Mosby Year Book, Inc.1994.

12. Potter P Perry A Fundamentals of Nursing- Concept, Process and Practice. Mosby Year Book; $3^{\text {rd }}$ Edition, 1993.

13. Virginia Henderson, Principles and Practice of Nursing, New York, MacMillan Publishing Co., 1970.

14. Sr. Nancy; Principle and Practice of Nursing; Vol.1,3 Edition; N R Brothers. Indore, 1992.

15. All Wales (2011). Point prevalence Survey of healthcare Associated infections, Medical device usage and antimicrobial usage. Report.

16. Allergranzi B, Bagheri Nejad S, Combescure c, Graafmans W, Attar H, Donaldoson L, Pittet D (2011). Burden of endemic health-care-Associated in infection in developing countries: systemic review and meta-analysis. Lancet;377 (9761):288-241.

17. Srivastava SP, Atal PR and singh RP. Studies on hospital infection. Ind J Surg 1969; 31:612-21.

18. Lilani SP, Jangale N, Chaudhary A, et al. Surgical site infection in clean and clean-contaminated cases. Ind J Med Microbiol 2005;23(4):249-52.

19. Ducel G, Fabry J, Nicolle L. Prevention of hospital acquired infections -a practical guide, $2^{\text {nd }}$ ed. Geneva: WHO; 2002

20. Green J, Wenzel RP. Post operative wound infection. Ann surg. 1977;185:264-8. 